\title{
Early tumor necrosis factor- $\alpha$ release from the pulmonary macrophage in lung ischemia-reperfusion injury
}

\author{
Babu V. Naidu, FRCS ${ }^{a}$ \\ Steven M. Woolley, MRCS ${ }^{a}$ \\ Alexander S. Farivar, MD \\ Robert Thomas, $\mathrm{BA}^{\mathrm{a}}$ \\ Charles H. Fraga, $\mathrm{MS}^{\mathrm{a}}$ \\ Christopher H. Goss, MD, MS, FCCP \\ Michael S. Mulligan, MD, FACS ${ }^{\mathrm{a}}$
}

From the Division of Cardiothoracic Surgery, Department of Surgery, ${ }^{\mathrm{a}}$ and Division of Pulmonary Medicine, ${ }^{b}$ University of Washington Medical Center, Seattle, Wash.

Received for publication Feb 27, 2003; revisions requested Aug 4, 2003; accepted for publication Aug 18, 2003.

Address for reprints: Michael S. Mulligan, MD, FACS, Box 356310, University of Washington Medical Center, 1959 NE Pacific St, Seattle, WA 98195 (E-mail: msmmd@u.washington.edu).

J Thorac Cardiovasc Surg 2004;127:1502-8 $0022-5223 / \$ 30.00$

Copyright (C) 2004 by The American Association for Thoracic Surgery

doi:10.1016/j.jtcvs.2003.07.037
Objective: Tumor necrosis factor- $\alpha$ is a proinflammatory mediator required for the development of experimental lung ischemia-reperfusion injury. The alveolar macrophage is a rich source of tumor necrosis factor- $\alpha$ in multiple models of acute lung injury. The present study was undertaken to determine whether the alveolar macrophage is an important source of tumor necrosis factor- $\alpha$ in lung ischemiareperfusion injury and whether suppression of its function protects against injury.

Methods: Left lungs of Long-Evans rats underwent normothermic ischemia for 90 minutes and reperfusion for up to 4 hours. Treated animals received gadolinium chloride, a rare earth metal that inhibits macrophage function. Injury was quantitated via lung tissue neutrophil accumulation (myeloperoxidase content), lung vascular permeability, and bronchoalveolar lavage fluid leukocyte, cytokine, and chemokine content. Separate samples were generated for immunohistochemistry.

Results: Tumor necrosis factor- $\alpha$ secretion occurred at 15 minutes of reperfusion and was localized to the alveolar macrophage by immunohistochemistry. In gadolinium-treated animals, lung vascular permeability was reduced by $66 \%$ at 15 minutes $(P<.03)$ of reperfusion and by $34 \%$ at 4 hours $(P<.02)$ of reperfusion. Suppression of macrophage function resulted in a $35 \%$ reduction in lung myeloperoxidase content $(P<.03)$ and similar reductions in bronchoalveolar lavage leukocyte accumulation. Tumor necrosis factor- $\alpha$ and microphage inflammatory protein- $1 \alpha$ protein levels were markedly reduced in the bronchoalveolar lavage of gadolinium-treated animals by enzyme-linked immunosorbent assay.

Conclusions: The alveolar macrophage secretes tumor necrosis factor- $\alpha$ protein by 15 minutes of reperfusion, which orchestrates the early events that eventually result in lung ischemia-reperfusion injury at 4 hours. Gadolinium pretreatment markedly reduces tumor necrosis factor- $\alpha$ elaboration, resulting in significant protection against lung ischemia-reperfusion injury.

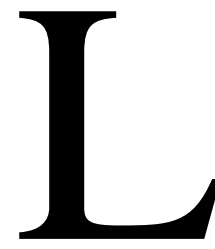

ung ischemia-reperfusion injury (LIRI) is a major complication of lung transplantation and pulmonary thromboendarterectomy. It is associated with an increase in vascular permeability that is manifest pathologically as an edematous lung infiltrated by inflammatory cells. ${ }^{1}$ In previously published animal models, the vascular injury has been biphasic in nature. ${ }^{2}$ Although the late phase is dependent on neutrophil recruitment and activation, the early injury is neutrophil-independent and occurs by 15 minutes of reperfusion. As early injury occurs well before significant tissue neutrophil infiltration has occurred, it is likely dependent on a resident cell type such as the alveolar macrophage (AM). AM, via their ability to secrete oxygen 
and nitrogen-derived free radicals and proinflammatory cytokines such as tumor necrosis factor- $\alpha$ (TNF- $\alpha$ ), have been shown to play a central and functional role in a variety of acute lung injury models. ${ }^{3-5}$ In response to oxidant stress in vitro, the AM rapidly secretes TNF- $\alpha .{ }^{6}$ TNF- $\alpha$ is believed to potentiate the release of chemokines and cytokines, increase lung vascular permeability, and modulate the eventual recruitment and activation of neutrophils (effector cells believed to mediate late reperfusion injury). These notions have previously been published in a lung ischemia-reperfusion model as there was a marked reduction of neutrophils found in bronchoalveolar lavage fluid after anti-TNF- $\alpha$ antibody pretreatment. ${ }^{7,8}$

Gadolinium chloride is a rare earth metal that is known to inhibit macrophage function in vivo and has been used previously to define macrophage function in various experimental models. ${ }^{4,5}$ Given that the early changes in vascular permeability are likely dependent on a resident cell and that the secretion of TNF- $\alpha$ is critical to the development of LIRI, we hypothesized that AM would be an important source of TNF- $\alpha$ and that their suppression with gadolinium chloride would be protective against acute reperfusion injury.

\section{Methods}

\section{Reagents}

All reagents, including gadolinium chloride, were purchased from Sigma Chemical (St Louis, Mo) unless otherwise specified.

\section{Animal Model}

Pathogen-free Long-Evans rats (Simonsen Labs, Gilroy, Calif), weighing 250 to $300 \mathrm{~g}$, were used for all experiments. All animals received humane care in compliance with the guidelines for care and use of laboratory animals published by the National Society for Medical Research and the National Institute of Health. A warm in situ ischemia-reperfusion model was utilized as has been described previously. ${ }^{9}$ Anesthesia was induced with pentobarbital $(35 \mathrm{mg} / \mathrm{kg}$ ) and animals were ventilated by tracheostomy (Harvard Apparatus Inc, Holliston, Mass). All animals received $0.2 \mathrm{mg}$ of atropine intramuscularly and $50 \mathrm{U}$ of intravenous heparin. Anesthesia was maintained with inhaled halothane. The left lung was mobilized atraumatically through an anterolateral thoracotomy and the left pulmonary artery, veins, and bronchus were occluded with a noncrushing microvascular clamp. At the end of the 90-minute ischemic period, the clamp was removed and the lung was ventilated and reperfused for periods up to 4 hours. At the conclusion of the reperfusion period, blood samples were obtained from the inferior vena cava, the heart-lung block was rapidly excised, and the pulmonary circulation was flushed with $20 \mathrm{~mL}$ of saline through the main pulmonary artery.

Treated animals received $7 \mathrm{mg} / \mathrm{kg}$ of intravenous (IV) gadolinium chloride 24 hours prior to injury, and control animals received an equivalent volume of saline. A third group received $7 \mathrm{mg} / \mathrm{kg} \mathrm{IV}$ gadolinium 24 hours prior to the experiment and did not undergo
}

ischemia or reperfusion. Unmanipulated, untreated animals were put to death for comparative purposes. All groups contained at least 4 animals.

\section{Lung Permeability Index}

To quantitate lung vascular injury secondary to ischemia and reperfusion, a permeability index was determined. ${ }^{125}$ I-radiolabeled bovine serum albumin $\left({ }^{125} \mathrm{I}\right.$-BSA; NEN Life Sciences, Boston, Mass), titrated to an activity of 800,000 counts per minute (cpm) per dose, was intravenously injected in a final volume of 1 $\mathrm{mL}$ of $1 \% \mathrm{BSA} /$ phosphate-buffered saline solution 5 minutes prior to removal of the hilar clamp. At the end of the experiment, the radioactivity was quantitated in the left lung as well as in $1 \mathrm{~mL}$ of inferior vena cava blood using a gamma counter. The permeability index was calculated as follows: permeability index (PI) $=$ left lung $(\mathrm{cpm}) / 1.0 \mathrm{~mL}$ blood $(\mathrm{cpm})$. This ratio corrects for any variation in systemic blood levels of radioactivity and provides a reproducible measure of lung microvascular permeability. ${ }^{9}$

\section{Myeloperoxidase Assay}

Myeloperoxidase (MPO) content was used to quantitate lung tissue neutrophil accumulation as described previously. ${ }^{9}$ Lung samples were homogenized in a phosphate buffer containing $0.5 \%$ hexadecyltrimethylammonium bromide. Samples were assayed for the ability to decompose $\mathrm{H}_{2} \mathrm{O}_{2}$ in the presence of O-dianisidine dihydrochloride by the change in absorption at $460 \mathrm{~nm}$ over 1 minute.

\section{Bronchoalveolar Lavage}

Additional animals underwent bronchoalveolar lavage (BAL) at the time of sacrifice. Through the tracheostomy, lungs were lavaged individually by clamping the contralateral hilum and instilling $3 \mathrm{~mL}$ of saline. This fluid was centrifuged ( $1500 \mathrm{~g}$ for 8 minutes at $4{ }^{\circ} \mathrm{C}$ ) to pellet the cells. The supernatant was snap frozen for cytokine analysis after the addition of a protease inhibitor. The red blood cells were lysed and the pellet was resuspended in saline. Cells were counted using a hemacytometer (Hausser Scientific, Reading, Pa). ${ }^{7}$

\section{Enzyme-Linked Immunosorbent Assay}

A sandwich enzyme-linked immunosorbent assay (ELISA) for macrophage inflammatory protein- $1 \alpha$ (MIP-1 $\alpha$ ) has been developed in our laboratory. ${ }^{10}$ Briefly, $10 \mu \mathrm{g} / \mathrm{mL}$ of anti-MIP- $1 \alpha$ antibody (Peprotech, Rocky Hills, NJ) was coated overnight at $4{ }^{\circ} \mathrm{C}$ in a 96-well (Dynex) immunoassay plate. After blocking with $1 \%$ BSA in saline $\left(30\right.$ minutes at $\left.37^{\circ} \mathrm{C}\right)$, samples and standards were added to each well for a 1 -hour incubation $\left(37^{\circ} \mathrm{C}\right)$. Secondary anti-MIP- $1 \alpha$ biotinylated antibody ( $2 \mu \mathrm{g} / \mathrm{mL}$; Peprotech) was added to each well (1-hour incubation at $37^{\circ} \mathrm{C}$ ). After a 30 -minute incubation with a streptavidin-horseradish-peroxidase conjugate (Pierce, Rockford, Ill), the assay was developed by adding ophenylenediamine dihydrochloride substrate. The reaction was stopped by adding $50 \mu \mathrm{L}$ of $3 \mathrm{~mol} / \mathrm{L} \mathrm{H}_{2} \mathrm{SO}_{4}$. The linear sensitivity range of the assay has been determined and the assay shows no cross reactivity with other chemokines. TNF- $\alpha$ ELISA was performed according to manufacturer's guidelines (R\&D Systems, Abingdon, UK). Samples and standards were run in triplicate, and well-to-well variation did not exceed $5 \%$. 


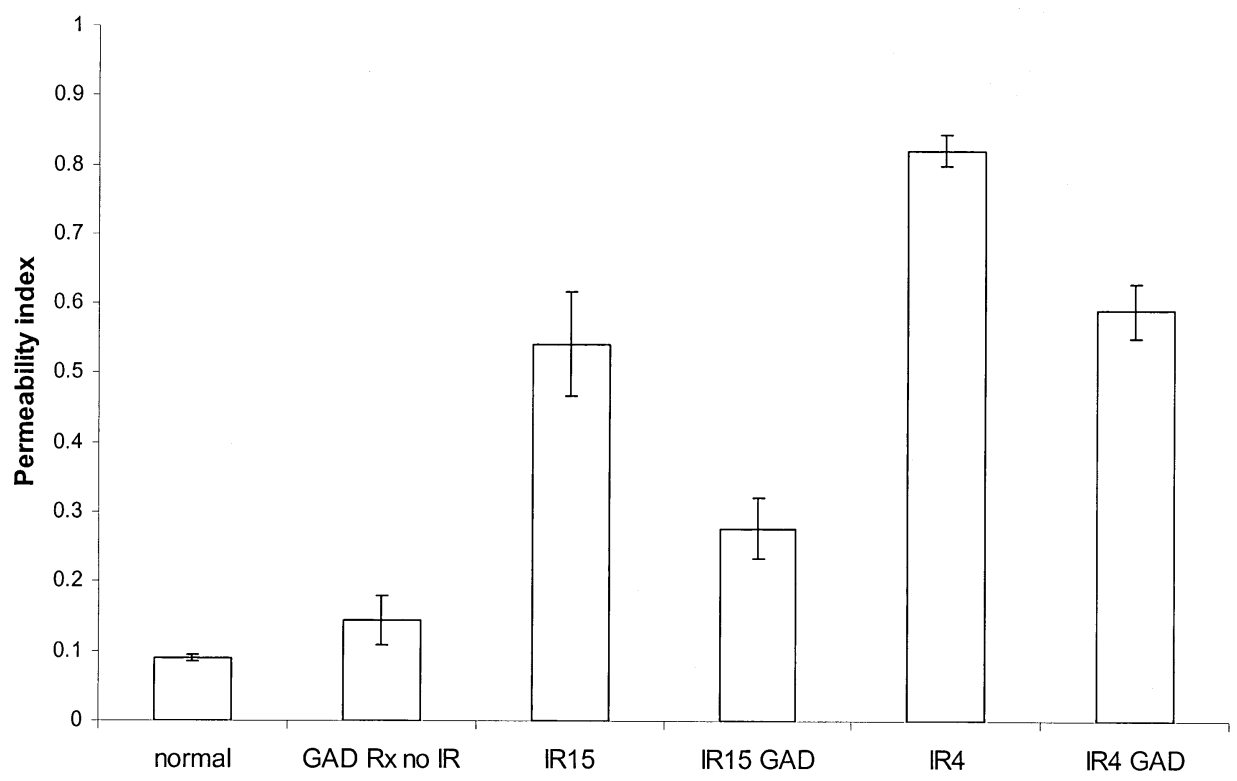

Figure 1. Lung vascular injury at $\mathbf{1 5}$ minutes and $\mathbf{4}$ hours of reperfusion.

\section{Immunohistology}

Whole lung tissue specimens were fixed in formalin and dehydrated, cleared, infiltrated, and embedded in paraffin. Specimens were cut into $5-\mu \mathrm{m}$ serial sections and baked overnight at $50^{\circ} \mathrm{C}$. In preparation for immunohistochemistry (IHC), sections were dewaxed and rehydrated through graded alcohols to a final distilled water wash. Following the blocking step, the primary anti-TNF- $\alpha$ (8 $\mu \mathrm{g} / \mathrm{mL}$; Peprotech), anti-caspase 3 (Cell Signaling, Beverley, Mass), or anti-macrophage (25 ucg/mL) antibody HAM-56 (DA$\mathrm{KO}$,Carpinteria, Calif) was incubated with the samples overnight at $4{ }^{\circ} \mathrm{C}$. Stained sections were examined using the image analysis software, Image Pro Plus (Media Cybernetics, Silver Spring, Md).

\section{Statistical Analysis}

Descriptive statistics (mean, standard errors) were used to describe the permeability index, MPO levels, cytokine levels, and BAL cell counts. Continuous variables were compared between groups using Mann-Whitney rank-sum tests. Stata 7.0 software (StataCorp, College Station, Tex) was used for the analysis.

\section{Results}

\section{Lung Permeability Index at 15 Minutes and 4 Hours of Reperfusion}

There was a slight increase in permeability index between unmanipulated, normal animals and animals receiving gadolinium pretreatment but no surgical manipulation $(P=$ .26). Animals undergoing 90 minutes of ischemia followed by 15 minutes of reperfusion (IR15) demonstrated a significant rise in mean permeability index compared with unmanipulated gadolinium-treated animals and normal animals. This rise was reduced in the gadolinium-treated group (IR15 $\mathrm{GAD}$ ) at 15 minutes of reperfusion by $66 \%$ (Figure 1).
There was also a significant increase in permeability index in control animals undergoing 90 minutes of ischemia followed by 4 hours of reperfusion. Gadolinium pretreatment caused a $34 \%$ reduction in permeability index at 4 hours of reperfusion (IR4 GAD) (Figure 1).

\section{Myeloperoxidase Content and Bronchoalveolar Lavage Cell Count}

Lung tissue neutrophil sequestration (MPO content) increased over 10 -fold and BAL cell count by 26 -fold in animals subjected to 90 minutes of ischemia followed by 4 hours of reperfusion (IR4) relative to unmanipulated normal animals. There was a $35 \%$ (Figure $2, A$ ) reduction in MPO and $40 \%$ reduction (Figure $2, B$ ) in BAL cell counts in gadolinium-treated animals at 4 hours of reperfusion (IR4 GAD) compared with untreated animals undergoing ischemia followed by 4 hours of reperfusion.

\section{ELISA for MIP-1 $\alpha$ and TNF- $\alpha$}

To determine whether inhibition of macrophage function was associated with a reduction in cytokine elaboration, MIP- $1 \alpha$ and TNF- $\alpha$ levels were studied in the lavage fluid of injured lungs with ELISA. These 2 mediators were selected because we have previously defined their function in the development of LIRI. MIP- $1 \alpha$ secretion increased significantly in animals that underwent 90 minutes of ischemia and 4 hours of reperfusion (IR4) compared with unmanipulated normal animals. Gadolinium treatment (IR4 GAD) was associated with a nonsignificant but $50 \%$ reduction in MIP- $1 \alpha$ levels. Similarly, TNF- $\alpha$ secretion increased by 24 -fold in animals undergoing ischemia then 4 hours reper- 
fusion (IR4) and was significantly reduced by $47 \%$ in gadolinium pretreated animals (IR4 GAD; Figure 3).

\section{TNF- $\alpha$ Immunohistochemistry}

Injured lungs were analyzed by IHC for expression of TNF- $\alpha$. There was minimal positive TNF- $\alpha$ staining in unmanipulated lungs (Figure 4, A). However, there was detectable TNF- $\alpha$ expression in mononuclear phagocytic cells located in the alveoli, interstitium, and around blood vessels after 90 minutes of ischemia only. These cells were confirmed to be AM by immunostaining with an anti-macrophage antibody (HAM 56). Following 15 minutes of reperfusion, the staining became much more intense, especially in perivascular AM around blood vessels (Figure 4, $B)$. The degree of positive staining was reduced in the gadolinium-treated group (Figure 4, $C$ ). Densitometric analysis was performed on multiple images and the results are shown in Figure 4, D.

\section{Caspase 3 Immunohistochemistry for Apoptosis}

In sections from untreated, unmanipulated lungs there was minimal positive caspase staining. However, in unmanipulated lungs from animals treated with gadolinium 24 hours previously, scattered mononuclear inflammatory cells stained intensely for caspase 3 . Densitometric analysis was performed on multiple images to quantitate the degree of apoptosis as assessed by caspase 3 staining. These results are shown in Figure 5. These cells were identified as alveolar and interstitial macrophages by staining of serial sections with a specific macrophage marker (HAM 56). Representative images stained for caspase 3 (Figure 6, A) and HAM-56 (Figure 6, B) are shown.

\section{Discussion}

TNF- $\alpha$ is secreted by a variety of cells including macrophages, monocytes, $\mathrm{T}$ cells, natural killer cells, and neutrophils. It also has an assortment of proinflammatory activities including leukocyte chemoattraction, phagocyte stimulation, vascular permeability modulation, enhancement of cytokine and chemokine production, and variable effects on cell growth and death. Functional roles for TNF- $\alpha$ have been identified in liver, ${ }^{11}$ heart, ${ }^{12}$ brain, ${ }^{13}$ kidney, ${ }^{14}$ hind limb,${ }^{15}$ and gut ${ }^{16}$ ischemia-reperfusion injury. These studies have demonstrated that TNF- $\alpha$ promotes injury in these models and that its blockade limits injury via decreased tissue neutrophil recruitment. Additionally, a role for TNF- $\alpha$ in remote lung injury has been shown in liver ${ }^{17}$ and intestine $^{18}$ ischemia-reperfusion models.

Studies have also defined a functional role for TNF- $\alpha$ in acute nonischemic lung injury secondary to lipopolysaccharide aspiration, ${ }^{19}$ immunoglobulin $\mathrm{G}$ immune-complex deposition, ${ }^{20}$ and anti-glomerular basement membrane antibody ${ }^{21}$ models, all of which were neutrophil-dependent. $\mathrm{We}^{7,22}$ and others ${ }^{8}$ have demonstrated a functional role for
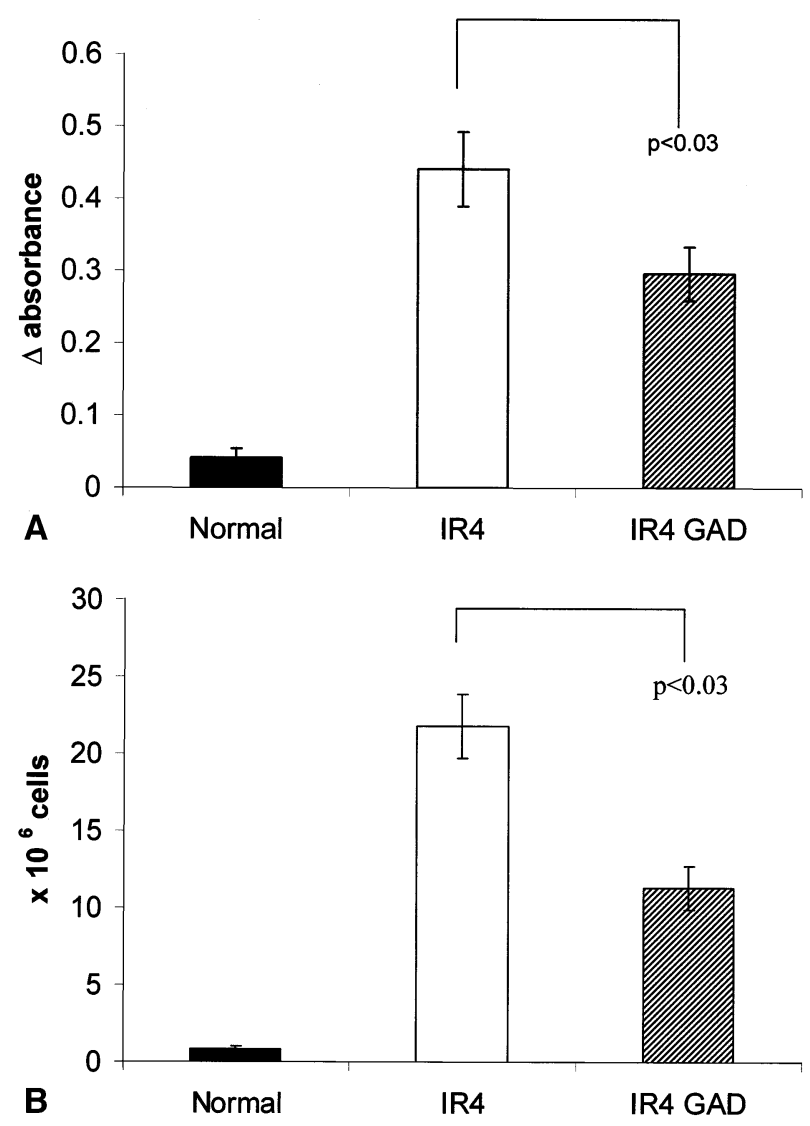

Figure 2. A, Lung tissue MPO content. B, Alveolar leukocyte cell counts.

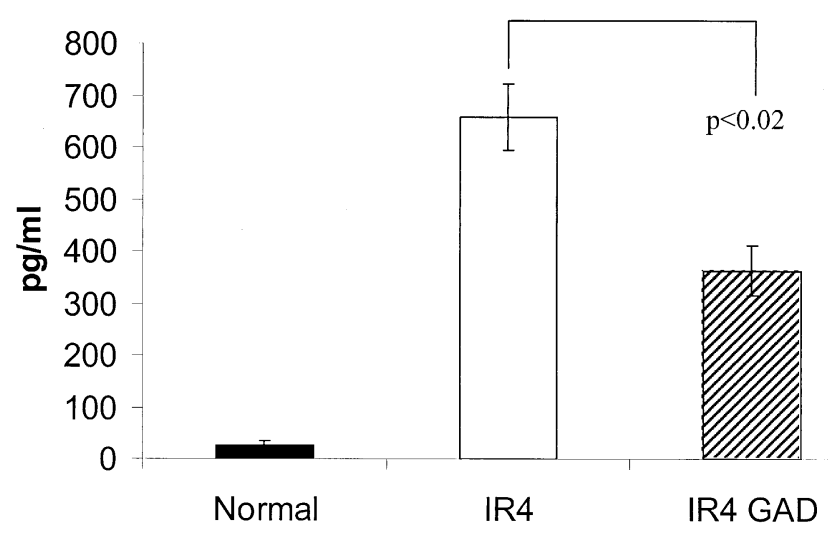

Figure 3. TNF- $\alpha$ lavage content.

TNF- $\alpha$ in LIRI. It appears TNF- $\alpha$ is released early in the injury process and then regulates the expression of other proinflammatory cytokines. ${ }^{7}$ These chemokines, in turn, promote neutrophil recruitment and activation.

The alveolar macrophage has an incredible range of biologic activities through its ability to synthesize and secrete an array of growth factors, cytokines, chemokines, 

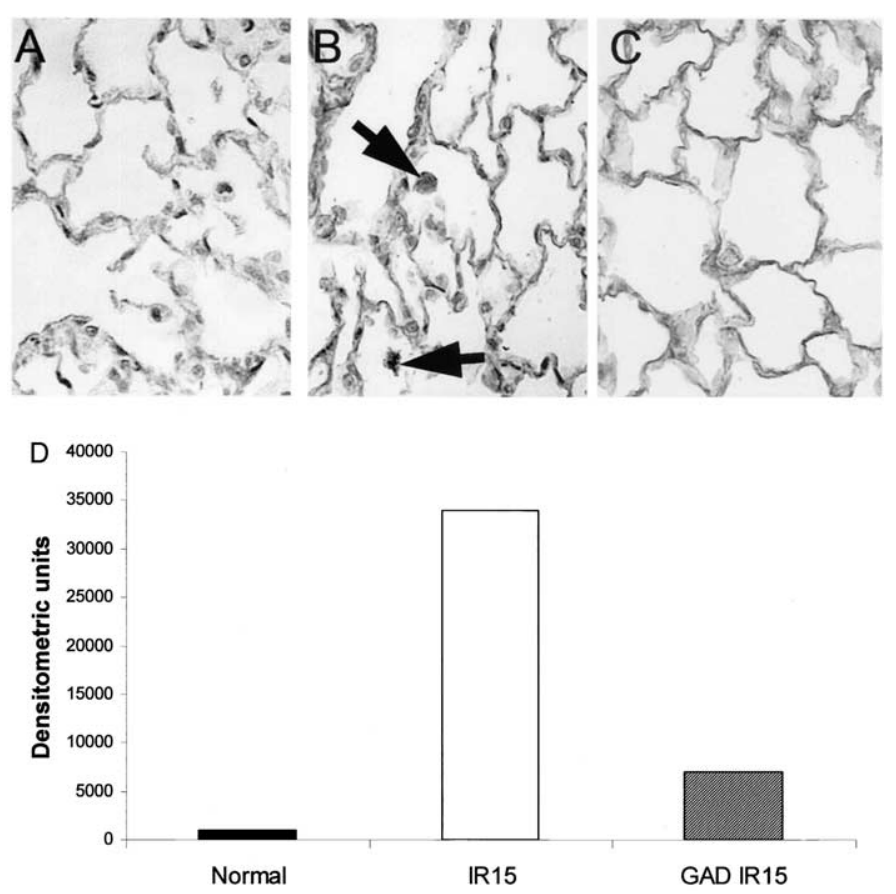

Figure 4. A-C, Immunohistochemistry for TNF- $\alpha$. D, Relative densitometry for TNF- $\alpha$ immunohistochemistry.

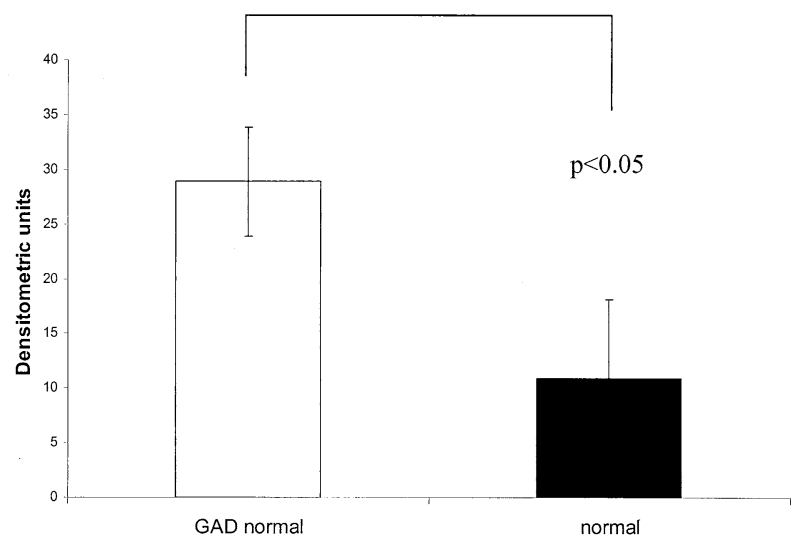

Figure 5. Relative densitometry for caspase-3 immunohistochemistry.

arachidonic metabolites, and oxygen radicals. Alveolar macrophages residing at the air-tissue interface and interstitial macrophages surrounding the vasculature are the early, rapid response immune effector cells responding to a wide variety of toxic, infectious, and allergenic stimuli. ${ }^{23}$ Additionally, suppression of AM function has been shown to be protective in a wide variety of models. ${ }^{3-5}$ Until recently, the role of the AM in LIRI has been unclear. Prior work suggested that inhibition of macrophage function with gadolinium improves pulmonary hemodynamics early in reperfusion in an isolated perfused lung model. ${ }^{24}$ However,
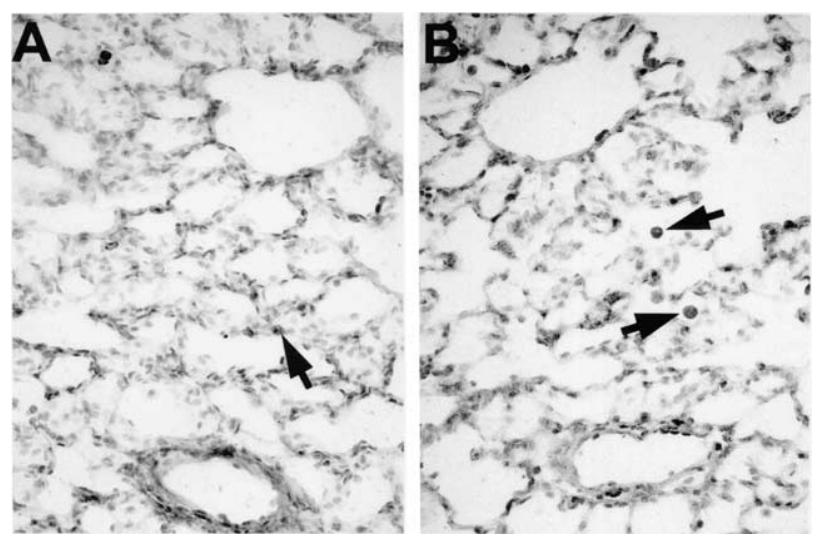

Figure 6. Immunohistochemistry for caspase-3 and HAM-56.

this was not associated with significant improvement in objective parameters of lung injury. Furthermore, in that study, the early improvement in injury associated with gadolinium treatment did not result in significant protective effects later in reperfusion. Therefore, this suggested that the AM may not be critical to the development of florid reperfusion injury. This contradiction to our present findings may be explained partly in that the isolated model likely does not reflect in situ physiology. We have previously shown marked protection against LIRI using clodronate-encapsulated liposomes in a warm in situ ischemia model. ${ }^{22}$ Macrophage depletion with intratracheally delivered liposomes is effective in targeting alveolar macrophages predominantly as they are avidly engulfed by AM, resulting in apoptosis shortly thereafter. ${ }^{25}$

Gadolinium is a well-recognized means of suppressing macrophages experimentally, ${ }^{4,5,26}$ but clinically is not practical because of the requirement of 24 hours of pretreatment. ${ }^{26}$ Furthermore, the precise mechanism by which it suppresses macrophage function is still poorly understood. The phagocytic and oxidative function of alveolar and interstitial macrophages, for example, may be unaffected by gadolinium treatment. ${ }^{26}$ However, in vitro incubation with gadolinium has been shown to induce apoptosis in alveolar macrophages,${ }^{27}$ and we have shown that in vivo gadolinium also exerts this phenomenon. The suppression of total body macrophage function, including those in the liver and spleen, the abnormalities induced in the clotting cascade, and the inhibition of hepatocyte function after gadolinium administration also limit its systemic utility. ${ }^{28}$ These limitations likely have little impact on the early, direct lung injury that is evident in this model. Gadolinium is also commonly used as a blocker for mechanogated cation channels and in this role has been shown to prevent high airway pressure-induced permeability changes in lungs in previous studies. ${ }^{29}$ It may be that some of the protection observed in the gadolinium-treated animals is due to protection against 
increase in permeability via modulation of stretch receptors. Given that early and late parameters of lung reperfusion injury are reduced with gadolinium treatment, coupled with the significant reduction of TNF- $\alpha$ expression, makes it highly likely that the AM plays a central role in inciting the events that lead to florid reperfusion injury. Targeting a specific cell type, rather than attempting to block specific mediators, may prove to be an effective strategy in preventing or treating LIRI. The present studies demonstrate that oxidant-stressed AMs are an important early source of proinflammatory mediators such as TNF- $\alpha$, which prime the endothelium, epithelium, and interstitial cells and ultimately foster the recruitment of inflammatory cells and the eventual development of tissue injury.

Early in lung IRI, TNF- $\alpha$ secretion is localized to the AM. In IHC samples at 1 hour of reperfusion, there was marked positive staining in AM, as well as endothelial cells and type II pneumocytes. This staining of these other cell types may be due to a paracrine phenomenon, as our previous in vitro work with both these latter cell types has not demonstrated significant TNF- $\alpha$ secretion subsequent to conditions of hypoxia and reoxygenation (data not shown). However, there has been evidence that rat type II pneumocytes can produce TNF- $\alpha$ in response to LPS stimulation. ${ }^{30}$ Therefore, further work will be required to determine the actual response to LIRI in regards to TNF- $\alpha$ secretion. As TNF- $\alpha$ has been shown directly to increase endothelial permeability in vitro and in vivo, ${ }^{31,32}$ macrophage-derived TNF- $\alpha$ may mediate the early transient rise in vascular permeability seen in this model. Therefore, macrophagederived TNF- $\alpha$ likely primes, both in an autocrine and paracrine fashion, several resident cell types to produce chemokines, cytokines, and adhesion molecules in response to oxidant stress. The reduction in the MIP- $1 \alpha$ and TNF- $\alpha$ secretion at 4 hours of reperfusion and the concomitant reduction in influx of neutrophils (MPO and BAL cell count) seen with gadolinium pretreatment support this notion.

\section{References}

1. Meyers BF, Lynch J, Trulock EP, Guthrie TJ, Cooper JD, Patterson GA. Lung transplantation: a decade of experience. Ann Surg. 1999; 230:362-70.

2. Eppinger MJ, Jones ML, Deeb M, et al. Pattern of injury and the role of neutrophils in reperfusion injury of rat lung. J Surg Research. 1995;58:713-8.

3. Lentsch AB, Czermak BJ, Bless NM, Van Rooijen N, Ward PA. Essential role of alveolar macrophages in intrapulmonary activation of NF-kappaB. Am J Respir Cell Mol Biol. 1999;20:692-9.

4. Pendino KJ, Meidhof TM, Heck DE, Laskin JD, Laskin DL. Inhibition of macrophages with gadolinium chloride abrogates ozone-induced pulmonary injury and inflammatory mediator production. Am J Respir Cell Mol Biol. 1995;13:125-32.

5. Fujii Y, Goldberg P, Hussain SN. Contribution of macrophages to pulmonary nitric oxide production in septic shock. Am J Respir Crit Care Med. 1998;157:1645-51.

6. VanOtteren GM, Standiford TJ, Kunkel SL, Danforth JM, Strieter RM.
Alterations of ambient oxygen tension modulate the expression of tumor necrosis factor and macrophage inflammatory protein-1 alpha from murine alveolar macrophages. Am J Respir Cell Mol Biol. 1995; 13:399-409.

7. Krishnadasan B, Naidu BV, Byrne K, et al. The role of the proinflammatory cytokines in lung ischemia reperfusion injury. J Thorac Cardiovasc Surg. 2003;2:261-72.

8. Eppinger MJ, Deeb GM, Bolling SF, Ward PA. Mediators of ischemiareperfusion injury of rat lung. Am J Pathol. 1997;150:1773-84.

9. Krishnadasan B, Naidu B, Rosengart M, et al. Decreased lung ischemia-reperfusion injury in rats after preoperative administration of cyclosporine and tacrolimus. J Thorac Cardiovasc Surg. 2002;123: 756-67.

10. Naidu BV, Krishnadasan B, Byrne K, et al. Regulation of chemokine expression by cyclosporine $\mathrm{A}$ in alveolar macrophages exposed to hypoxia and reoxygenation. Ann Thorac Surg. 2002;74:899-905.

11. Colletti LM, Kunkel SL, Walz A, et al. The role of cytokine networks in the local liver injury following hepatic ischemia reperfusion injury. Hepatology. 1996;23:506-14.

12. Gurevitch J, Frolkis I, Yuhas Y, et al. Anti tumor necrosis factor-alpha improves myocardial recovery after ischemia and reperfusion. $J \mathrm{Am}$ Coll Cardiol. 1997;30:1554-61.

13. Lavine SD, Hoffman FM, Zlokovic BV. Circulating antibody to tumor necrosis factor alpha protects rat brain from reperfusion injury. J Cereb Blood Flow Metab. 1998;18:52-8.

14. Donnahoo KK, Shames BK, Harken AH, Meldrum DR. The role of tumor necrosis factor in renal ischemia reperfusion injury. $J$ Urol. 1999;162:196-203.

15. Seekamp A, Warren JS, Remiock DG, Till GO, Ward PA. Requirements for tumor necrosis factor alpha and interleukin 1 in limb ischemia reperfusion injury. Am J Pathol. 1993;143:453-63.

16. Yao YM, Bahrami S, Redl H, Schlag G. Monoclonal antibody to tumor necrosis factor alpha attenuates hemodynamic dysfunction secondary to intestinal ischemia reperfusion injury in rats. Crit Care Med. 1996; 24:1547-53.

17. Colletti LM, Burtch GD, Remick GD, et al. The production of tumor necrosis factor alpha and the development of pulmonary capillary injury following hepatic ischemia reperfusion. Transplantation. 1990; 49:268-72.

18. Caty MG, Guice KS, Oldham KT, Remick DG, Kunkel SI. Evidence for tumor necrosis factor induced pulmonary microvascular injury after intestinal ischemia reperfusion injury. Ann Surg. 1990;212:694700 .

19. Johnston CJ, Finkelstein JN, Gelein R, Oberdorster G. Pulmonary cytokine and chemokine mRNA expression after LPS stimulation. Toxicol Sci. 1998;42:300-7.

20. Shanley TP, Peters JL, Jones ML, Chensue SW, Kunkel SL, Ward PA. Regulatory effects of endogenous interleukin 1 receptor antagonist protein in immunoglobulin $\mathrm{G}$ immune complex induced lung injury. J Clin Invest. 1996;97:963-70.

21. Mulligan MS, Lentsch AB, Shanley TP, Miyasaka M, Johnson KJ, Ward PA. Cytokine and adhesion molecule requirements for lung injury induced by anti-glomerular basement membrane antibody. Inflammation. 1998;22:403-17.

22. Naidu BV, Krishnadasan B, Farivar AS, et al. Early activation of the alveolar macrophage is critical to the development of lung ischemia reperfusion injury. J Thorac Cardiovasc Surg. 2003;126:200-7.

23. Brody AR. Whither goes the alveolar macrophage? Another small chapter is written on the localized response of this crucial cell. J Lab Clin Med. 1998;131:391-2.

24. Fiser SM, Tribble CG, Long SM, et al. Lung transplant reperfusion injury involves pulmonary macrophages and circulating leukocytes in a biphasic response. J Thorac Cardiovasc Surg. 2001;121:106975 .

25. Van Rooijen N, Sanders A, Van den Berg TK. Apoptosis of macrophages induced by liposome-mediated intracellular delivery of clodronate and propamidine. J Immunol Methods. 1996;193:93-9.

26. Bannenberg G, Lundborg M, Johansson A. Pulmonary macrophage function in systemic gadolinium chloride-pretreated rats. Toxicol Lett. 1995;80:105-7. 
27. Mizgerd JP, Molina RM, Stearns RC, Brain JD, Warner AE. Gadolinium induces macrophage apoptosis. J Leukoc Biol. 1996;59: 189-95.

28. Spencer AJ, Wilson SA, Batchelor J, Reid A, Rees J, Harpur E. Gadolinium chloride toxicity in the rat. Toxicol Pathol. 1997;25:24555.

29. Parker JC, Ivey CL, Tucker JA. Gadolinium prevents high airway pressure-induced permeability increases in isolated rat lungs. $J$ Appl Physiol. 1998;84:1113-8.
30. McRitchie DI, Isowa N, Edelson JD, et al. Production of tumor necrosis factor alpha by primary cultured rat alveolar epithelial cells. Cytokine. 2000;12:644-54.

31. van Griensven M, Stalp M, Seekamp A. Ischemia-reperfusion directly increases pulmonary endothelial permeability in vitro. Shock. 1999; 11:259-63.

32. Mark KS, Miller DW. Increased permeability of primary cultured brain microvessel endothelial cell monolayers following TNF-alpha exposure. Life Sci. 1999;64:1941-53. 